\title{
Intramuscular Hydatid Cyst: Report of an Unusual Case
}

\author{
Saniye Göknil Çalık', Mustafa Çalık², Mihrican Yeşildağํ․ Hıdır Esme² \\ 'Department of Emergency Medicine, Konya Training and Research Hospital, Konya, Turkey \\ ²Department of Thoracic Surgery, Konya Training and Research Hospital, Konya, Turkey \\ ${ }^{3}$ Department of Chest Diseases, Konya Training and Research Hospital, Konya, Turkey
}

\begin{abstract}
Introduction: Hydatid disease, known since Hippocrates' time, is still a serious trouble. Intramuscular hydatid cyst is extremely rare, at less than $1 \%$ of all locations. We describe herein a patient with an intramuscular hydatid cyst that has a very low chance of being experienced outside endemic areas by many physicians.

Case Report: A 64-year-old man was admitted to our hospital with a six-month history of a painless slow-growing mass in his left hemithorax. Upon physical examination, there was a $6 \times 4.5-\mathrm{cm}$, non-tender, mobile, smoothly outlined mass on the left latissimus dorsi muscle. Radiological assessments revealed two cystic pulmonary nodules in the right inferior lobe and no other organ involvement. The patient underwent a two-step surgery. Diagnosis was verified on histopathological examination. After the operation, medical treatment with albendazole $(10 \mathrm{mg} / \mathrm{kg} /$ day $)$ for three months was prescribed.

Conclusion: Hydatid disease can be found in any skeletal muscle or, indeed, anywhere in the body. Due to its rarity and unusual location, diagnosis can be missed easily in a busy and crowded ER. Hydatid disease should be kept in mind in the differential diagnosis of all soft tissue lesions, even though they located in the muscle, particularly in endemic zones such as Turkey.
\end{abstract}

Keywords: Intramuscular, hydatid, cyst

Received: 03.01.2016 Accepted: 25.01.2016 Available Online Date: 16.02.2016

\section{Introduction}

Hydatid disease or Echinococcosis, caused by the cestode Echinococcus granulosus larvas and known ever since Hippocrates' time, is still a serious trouble. It is an indigenous zoonotic infection in many areas where sheep and goat farming and cattle farming is common, such as South America, Africa, the Mediterranean, the Middle East, India, Australia, and New Zealand (1, 2). Hydatid disease can be found any part of the body, although the most commonly involved are the liver (75\%) and lungs (15\%). Intramuscular hydatid cyst attacking a single muscle is an unusual condition as the skeletal muscle contains high lactic acid concentration and contractile activity-like mechanical factors (1-3); it occurs in less than 1\% of all locations (4).

In this study, we aimed to describe a patient with intramuscular hydatid cyst that has very low chance of being detected outside the endemic areas by many physicians.

\section{Case report}

A 64-year-old man was admitted to our hospital with a six-month history of a painless slow-growing mass in his left hemithorax. He had no other complaints. His medical history and physical examination were unremarkable except for mass on the left latissimus dorsi muscle. Upon physical examination, there was a $6 \times 4.5-\mathrm{cm}$, non-tender, mobile, smoothly outlined mass on the left latissimus dorsi muscle. There were no signs of skin inflammation, such as induration, heat, or redness. The mass was palpated subcutaneously over the left latissimus dorsi muscle (Figure 1). All routine laboratory tests were normal. Thorax computed tomography (CT) showed two cystic pulmonary nodules, $4.3 \times 3.2$ and $1.5 \times 2 \mathrm{~cm}$ in diameter, in the right inferior lobe. Magnetic resonance imaging (MRI) demonstrated a well-circumscribed multilocular cyst (largest size, $6 \times 4.5 \mathrm{~cm}$ ) in the left latissimus 
Table 1. The Gharbi classification for hydatid cysts

\begin{tabular}{|c|c|}
\hline Type I & Purely cystic lesion \\
\hline Type ॥ & Germinative membrane is detached within parts of the cyst \\
\hline Type III & Multicystic lesion separated by septae \\
\hline Type IV & The cyst is degenerated with a pseudo-solid appearance \\
\hline Type V & The pseudo-solid cyst and ectocyst are calcified \\
\hline
\end{tabular}

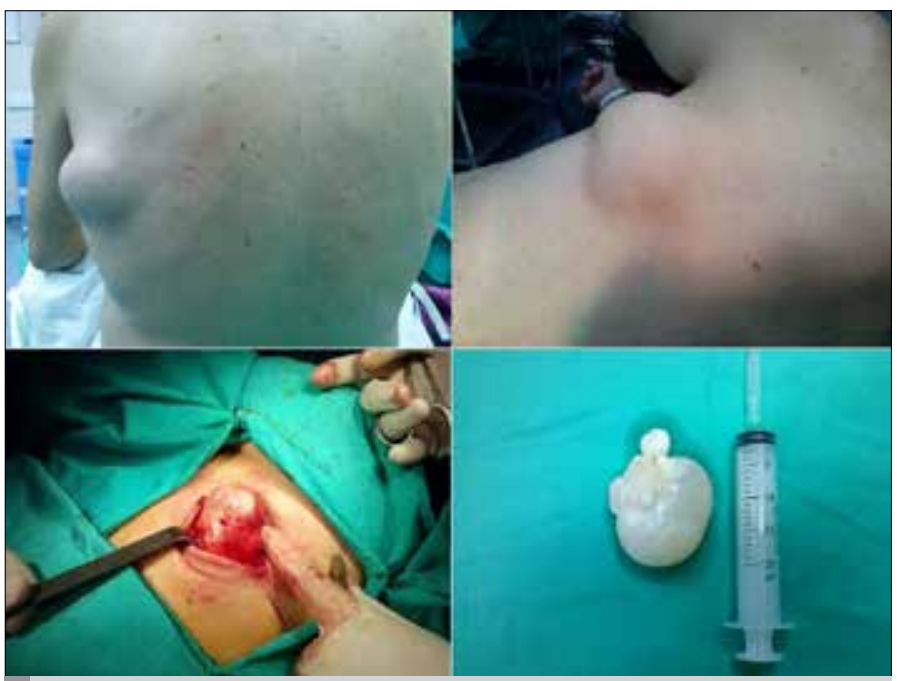

FIGURE 1. The clinical finding (mass in the left latissimus dorsi muscle) and surgical specimen (the cyst was resected intact with surrounding tissues)
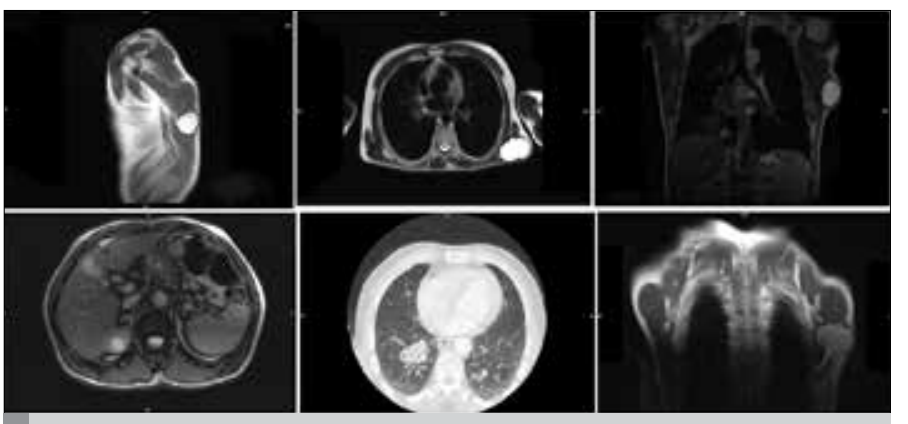

FIGURE 2. Radiological images (MRI) of the cyst

dorsi muscle. Additional radiological assessments revealed no other organ involvement.

All procedures were performed under general anesthesia in the operating room. The patient underwent a two-step surgery. The first step was excision of the cyst with the surrounding muscle tissue in his left hemithorax. The next step involved cystectomy plus capitonnage performed on the lung lesions through the right posterolateral thoracotomy. Both surgical interventions were carried out with the patient in the lateral decubitus position. Diagnosis was verified on histopathological examination. After the operation, medical treatment with 20-day single-cycle of albendazole $(10 \mathrm{mg} / \mathrm{kg} /$ day $)$ prescribed. The patient did not show any perioperative complications on 9th postoperative day and was discharged without any com- plaints; he was followed up for seven months without any signs of recurrence.

\section{Discussion}

Four species of the genus Echinococcus; E. granulosus, E. multilocularis, E. vogeli, and E. oligarthus are known to cause infections such as cystic hydatid disease, alveolar hydatid disease, and polycystic hydatid disease in human beings (5). Of them, the most common one attacking human beings is E. granulosus (6). Two location areas are called for the life cycle of Echinococcus granulosus. Carnivores such as dogs and wolves are the definitive hosts that harbor mature tapeworms in their intestines. Herbivores such as sheep and cattle act as intermediate hosts that ingest the eggs from which the embryos escape, penetrate the intestinal mucosa, enter the portal circulation, and then are trapped in the liver and lungs. Thus, the nine-tenth are involved in the liver and lung. The life cycle is completed once the carnivores eat the infected entrails of the intermediate hosts. It is idiopathically dead-end for the parasites in the random host human beings (5). A few cysts may leak into the circulation, but they are only responsible in $10 \%$ of all cases for the rarely involved organs such as the spleen, pancreas, gallbladder, adrenal gland, pelvis, seminal vesicle, heart, bone, breast, kidney, thyroid gland, and soft tissues (1). It is still obscure and debatable how hydatid cyst is transmitted, generated, and developed in rare locations; however, distinctive theories have been proposed-one of the most agreed theories is the shunt-escape theory (7).

The signs and symptoms of the hydatid disease vary according to the involved organ, the site, the effects on the adjacent tissues, complications after rupture, secondary infection, and immunological reactions (8). The first and most common symptom in our patient was a slowgrowing painless mass, and this symptom was compatible with the literature. The helpful diagnostic and classification ways of cysts are ultrasonography, CT, and MRI (2). Intramuscular hydatidosis have been classified according to the Gharbi classification (Table 1). Multiple adjacent Gharbi type III cysts (multicystic fluid collections with septae) each with 6-cm diameters occurred in the left latissimus dorsi muscle in radiological assessments (Figure 2). Indirect hemagglutination testing was positive for E. granulosus at a titer of 1:800.

Open surgery is the most favored method despite the current treatment methods that have been employed in the liver cysts, including surgery; percutaneous methods such as puncture, aspiration, injection, and re-aspiration (PAIR); percutaneous drainage without reaspiration; and medical management with benzimidazole derivatives (3). During excision of the cyst, a surgeon must be careful to avoid spilling its contents as anaphylaxis and dissemination can occur. If this is not achieved, surgery cannot be curative and recurrence with high morbidity is highly probable (1). We performed an excision for intramuscular cyst and cystectomy plus capitonnage for the lung in our patient. In addition to chemotherapy, antihelmintic drugs, such as mebendazole $(50 \mathrm{mg} / \mathrm{kg} /$ day $)$ or albendazole $(10 \mathrm{mg} / \mathrm{kg} /$ day), must be used. Although there is no consensus about the duration of chemotherapy, which varies between 4 and 6 months in the literature, in our opinion, a treatment of 3 months seems to be sufficient. 


\section{Conclusion}

To our knowledge, there have been very few reports of intramuscular hydatidosis latissimus dorsi involvement. Hydatid disease can be found in any skeletal muscle or, indeed, anywhere in the body. Due to its rarity and unusual location, diagnosis can be missed easily in busy and crowded ERs. Hydatid disease should be kept in mind in the differential diagnosis of all soft tissue lesions, even when they are located in the muscle, particularly in endemic zones such as Turkey.

Informed Consent: Written informed consent was obtained from patient who participated in this case.

Peer-review: Externally peer-reviewed.

Author Contributions: Concept - S.G.Ç., M.Ç.; Design - S.G.Ç., M.Ç.; Supervision - S.G.Ç., M.Ç.; Materials - S.G.Ç., M.Ç., M.Y., H.E.; Data Collection and/or Processing - S.G.Ç., M.Ç.; Analysis and/or Interpretation - S.G.Ç., M.Ç.; Literature Review - S.G.Ç., M.Ç.; Writer - S.G.Ç., M.Ç.; Critical Review - S.G.Ç., M.Ç.

Conflict of Interest: The authors declared no conflict of interest.

Financial Disclosure: The authors declared that this study has received no financial support.

\section{References}

1. Safioleas M, Nikiteas N, Stamatakos M, Safioleas C, Manti CH, Revenas C, et al. Echinococcal cyst of the subcutaneous tissue: a rare case report. Parasitol Int 2008; 57: 236-8. [CrossRef]

2. Duzgun N, Esme H, Duran F. M, Calik M, Cetin, B. Hydatid Disease of the Spine: Case Report Turkiye Klinikleri Arch Lung 2014; 15: 79-82

3. Ormeci N, Idilman R, Akyar S, Palabiyikoğlu M, Coban S, Erdem H, et al. Hydatid cysts in muscle: a modified percutaneous treatment approach. Int J Infect Dis 2007; 11: 204-8. [CrossRef]

4. Jerbi Omezzine S, Abid F, Mnif H, Hafsa C, Thabet I, Abderrazek A, et al. Primary hydatid disease of the thigh. A rare location. Orthop Traumatol Surg Res 2010; 96: 90-3. [CrossRef]

5. Parray FQ, Ahmad SZ, Sherwani AY, Chowdri NA, Wani KA. Primary paraspinal hydatid cyst: a rare presentation of Echinococcosis. Int J Surg 2010; 8: 404-6. [CrossRef]

6. Sogut O, Ozgonul A, Bitiren M, Kose R, Cece H. Primary hydatid cyst in the deltoid muscle: an unusual localization. J Infect Dis 2010; 14 Suppl 3:e347-8. [CrossRef]

7. Vecchio R, Marchese S, Ferla F, Spataro L, Intagliata E. Solitary subcutaneous hydatid cyst: review of the literature and report of a new case in the deltoid region. Parasitol Int 2013; 62: 487-93. [CrossRef]

8. Ozgonul A, Sogut O, Cece H, Aydın S, Kürkcüoglu IC. Co-occurrence of diaphragmatic and serratus anterior muscle hydatidosis: an unusual localization. J Emerg Med 2012; 43: e219-22. [CrossRef] 